was narrated receiving it with more or less marked incredulity.

A short time ago, however, Señor Ameghino was shown a number of fresh ossicles from Patagonia, of somewhat smaller size than coffee-berries, which he at once recognised as comparable with the somewhat larger bones commonly found in association with the remains of certain species of Mylodon from the pampean deposits of the Argentine, and which have always been regarded as indicating the presence of a dermal armour in those animals. These ossicles, it appears, were extracted from a badly preserved body-skin, which seems to have been exposed for some time to the action of the weather, and consequently to have become considerably discoloured. In thickness this skin measured about two centimetres and its hardness and toughness were such that it could be cut only with a chisel or hatchet. In its deeper layer were embedded the ossicles; and in those places where it was least damaged it was covered with coarse reddish grey hair, from 4 to 5 centimetres in thickness.

The skin evidently belonged to an animal hitherto unknown to science ; and, in spite of the absence of the limbs, the presence of the ossicles seems to afford decisive evidence that it indicates an existing small representative of the ground-sloths, more or less intimately related to the typical group of the genus Mylodon. Moreover, in the colour of the hair it agrees with Lista's description of his unknown animal, which he confidently asserted to be an Edentate. Señor Ameghino seems, therefore, to be fully justified in regarding the two specimens as pertaining to one and the same species, and that species to be a living representative of the Megalotheriida, hitherto known only in the fossil. For this animal the name of Neomylodon listai is proposed, but the specific title should be amend ed to listce.

Dermal ossicles are only known to be developed in certain species of Mylodon and Glossotherium, and have not been detected among the remains of the smaller ground-sloths characteristic of the Patagonian formations. The presumption accordingly is that the new animal is more or less closely allied to these genera, from which, indeed, its right to distinction has yet to be demonstrated.

This animal is doubtless nocturnal, and also of rare occurrence, and some time may therefore probably elapse before a perfect specimen is obtained. Till that event happens naturalists must be content with the fact that a survivor of the old ground-sloths exists in the interior of Patagonia.

\section{REPORT ON A NATIONAL PHYSICAL} LABORATOR $Y$.

THE Committee appointed in August, I897, to conside the desirability of establishing a National Physical Laboratory have issued their report. The Committee consisted of Lord Rayleigh, F.R.S. (chairman), Sir Courtenay Boyle, K.C.B., Sir Andrew Noble, K.C.B. F.R.S., Sir John Wolfe Barry, K.C.B., F.R.S., Prof. W. C. Roberts-Austen, C.B., F.R.S., Mr. Robert Chalmers, Prof. A. W. Rücker, F.R.S., Mr. Alexander Siemens, and Dr. T. E. Thorpe, F.R.S. The questions referred to them were as follows:-

"To consider and report upon the desirability of establishing a National Physical Laboratory for the testing and verification of instruments for physical investigation for the construction and preservation of standards of measurement ; and for the systematic determination of physical constants and numerical data useful for scientific and industrial purposes - and to report whether the work of such an institution, if established, could be associated with any testing or standardising work, already performed wholly or partly at the public cost."

NO. I 5 IO, vOL. 58 ]
The following are extracts from the report of the Committee :-

In general, the committee are of opinion that the appliances and facilities of the Standards Office and of the Electrical Standardising Laboratory are fairly adequate for the performance of their statutory duties. They understand, however, that on account of the want of means for the chemical analysis of the materials used in the construction of standards, those offices would find some difficulty, without extraneous assistance, with regard to any new standards that might be required.

They further desire to point out that many physical constants and data and numerical expressions are necessarily used in connection with standards and the standardising of instruments. Some of the data now in use at the Standards Office are known to require correction, and in the case of others further investigations appear to be desirable. There is, however, no legal obligation on the Board of Trade to establish new data and numerical expressions, and, in consequence of the smallness of the staff of the office the work of the Department is limited to that which is strictly enjoined by the Acts of Parliament. The Department is at the present time chiefly dependent for more exact knowledge on such investigations as may be undertaken at the Bureau International des Poids et Mesures at Paris, or by foreign institutions similar to that contemplated in this country.

There is much evidence that further facilities are needed by the public for standardising and verifying of instruments, both for scientific and commercial use ; and also that it would be of great benefit to trade if means were provided for the public testing of the quality of certain classes of materials. In particular the committee desire to draw attention to the evidence which has been laid before them as to the difficulties arising in certain Government departments in their dealings with contractors and others which might be overcome by the establishment of an independent testing authority. It would neither be necessary nor desirable to compete with or interfere with the testing of materials of various kinds as now carried out in private or other laboratories; but there are many special and important 'tests and investigations into the strength and behaviour of materials which might be conducted with great advantage at a laboratory such as is contemplated in the reference. As illustrations wé may mention investigations into the behaviour of metals and other substances under continuous or alternating stresses, which investigations are not, so far as we know, conducted at the present time at any testing institution in this country, and which could only be undertaken with satisfactory and authoritative results at a public laboratory.

For many years the testing of certain instruments has been carried out at the Kew Observatory under the direction of the Kew Observatory Committee of the Royal Society. There is much evidence that the existence of these tests has been of great benefit to both science and industry. On the one hand it enables the maker to give, or the purchaser to obtain, an independent and trustworthy statement as to the quality of the instrument. On the other hand, the existence of the tests has led in many cases to a marked improvement of the instruments ; and similar results may be anticipated by an extension of these facilities to other branches of industry.

The Kew Observatory is a Government building leased to the Royal Society at a nominal rent, situate in the Old Deer Park, Richmond, which is Crown property. The institution has no endowment, the Gassiot Fund producing about 470l. per annum. From the Meteorological Office it receives annually $400 \%$., part of which is the ordinary grant made to a first-class meteorological station, the remainder being for scientific assistance. The fees received for the verification and testing of instruments amount to about $2000 /$. per annum. The institution is self-supporting, and has usually a small annual balance which is devoted to scientific investigation and to the extension of the work, including the erection of new buildings, when required. The funds at the disposal of the Observatory Committee are, however, quite inadequate to any considerable extension of its operations. The work done with restricted means has been very useful. The total number of instruments annually verified or tested is about 22,000. Among these are included watches, thermometers, sextants, barometers, and other apparatus used for scientific or industrial purposes. Evidence was given of the beneficial effect which Kew has exerted on the watchmaking trade, and it is noteworthy that this is due to the introduction of tests for which there was little or no previous demand on the 
part of the trade, though there is now keen competition among the best makers to secure a high place in the report which is annually issued.

In the opinion of the committee the principles which underlie the proposal for the establishment of a national physical laboratory have been tested on a comparatively small scale at the Kew Observatory with the most satisfactory results.

In addition to the physical constants and numerical data needed in connection with standards, there are numerous facts, a knowledge of which would be of great value to science and industry. The determination of such data usually involves an investigation as to the method of making the determination, and a considerable expenditure of skilled labour in carrying out the determination. The committee are of opinion that, although the former part of this work will in general be initiated by individual experimenters of great skill and originality, it may in special cases be usefully undertaken by a public body. It is rather to the improvement in the details of the method of making the determination that they think that the work of a public institution will for the most part be directed. This cannot usually be carried out by private investigators on account of the expense and the length of time over which the experiments must extend. The scientific reputation to be gained is often incommensurate with the labour involved; and even when the results are of industrial importance in many cases they cannot be protected by patents.

There is evidence that many questions of this nature are partially investigated for technical purposes by private persons, the results being not infrequently kept isecret. More complete investigations carried out at a public institution and freely published would often be of great service to industry, and there is reason to believe that a large part of the cost of such work might be defrayed by the persons directly interested in the results.

One difficulty in connection with a scheme for the determination of constants and data arises from the fact that the number of sub. jects which might be pressed for investigation would be very large. The opinion was, however, generally expressed by the witnesses that a strong governing body would have no difficulty in selecting those branches of work which were the most important, and that it would be possible to confine the work of the proposed institution, if established, within moderate limits. Nearly all the witnesses, also, have expressed the opinion that those inter ested in industry as well as persons devoted to the study of pure science would be willing that the Royal Society should be ultimately responsible for the management of the proposed institution, provided that industry were adequately represented on the governing body, and that the choice of the members of that body, though nominated by the Council of the Royal Society, were not confined to Fellows of the Society.

After consideration of the evidence the committee have come to the conclusion that an institution should be established for standardising and verifying instruments, for testing materials, and for the determination of physical constants. Work useful both to science and industry could therein be performed for which no adequate provision is at present made, either in this country or at the Bureau International des Poids et Mesures. Such work could not, or, at all events, in all probability would not, be undertaken by individual workers, or by institutions primarily devoted to education. In the opinion of the committee the proposed institution should be established at the national expense on lines similar to, though not at present on the scale of, the Physikalisch-technische Reichsanstalt referred to above. The possibility of future extension should, however, be kept in view from the first.

To secure the efficient performance of the work, the committee are of opinion that the director of the institution should be a man of high scientific attainments, and should act under a governing body containing representatives of both science and industry. The director should not be called upon or allowed to undertake work not connected with the institution except with the consent of the governing body. $\mathrm{He}$ would require the support of an adequate staff. As regards locality, while it is desirable that the institution should be near London, it is necessary that the site be free from mechanical and electrical disturbance.

Among the most important questions considered by the com. mittee was whether the proposed institution should be founded independently or should be a development of an existing institution. The duties of the Board of Trade, as custodian of ccrtain

$$
\text { NO. I } 5 \text { IO, VOL. } 58 \text { ] }
$$

standards, are defined by statute, and the committee consider that it is undesirable to alter existing arrangements in this respect. They are of opinion that the proposed laboratory if established should be managed by a governing body constituted and appointed as hereinafter described, and should not be under the direct control of a Government department. They recommend that the Board of Trade, as custodian of the standards, should be placed in close connection with the said governing body.

The character of the work done at the Kew Observatory suggests that all that is really necessary might be attained by the development of that institution.

\section{Recommendations.}

(I) That a public institution should be founded for standardizing and verifying instruments, for testing materials, and for the determination of physical constants.

(2) That the institution should be established by extending the Kew Observatory in the Old Deer Park, Richmond, and that the scheme should include the improvement of the existing buildings, and the erection of new buildings at some distance from the present observatory.

(3) That the Royal Society should be invited to control the proposed institution, and to nominate a governing body, on which commercial interests should be represented, the choice of the members of such body not being confined to Fellows of the society.

(4) That the permanent secretary of the Board of Trade should be an ex officio member of the governing body; and that such body should be consulted by the Standards Office and the Electrical Standardising Department of the Board of Trade upon difficult questions that may arise from time to time or as to proposed modifications or developments.

\section{NOTES.}

IN connection with the forthcoming conference upon an International Catalogue of Scientific Literature, a reception will be held at the Royal Society on Monday next, October ro. A dinner has been arranged by the President for Fellows of the Society and their friends who are interested in the subject of the Catalogue. It will take place at the Hôtel Métropole on Tuesday, October I I.

IN connection with the opening of the winter session of the Charing-cross Hospital Medical School on Monday, Prof. Rudolf Virchow, Director of the Berlin Pathological Institute, delivered the second of the Huxley lectures, his subject being "Recent Advances in Science, and their Bearing on Medicine and Surgery." Lord Lister, President of the Royal Society, uccupied the chair, and a large number of members of the medical profession, and distinguished men of science were present. Prof. Virchow was most cordially received, and his address, printed in another part of this number, was followec with deep interest and attention.

Mr. T. MELlard Reade informs us that the gypsum boulder, weighing at least thirteen tons, found in the Boulder Clay of Great Crosby, and described in a previous number of Nature (p. $\mathbf{3}_{32}$ ), has been presented to the District Council by Mr. Peters, and is now being moved from its original bed with the intention of erecting it in an open space in Liverpool Road, Great Crosby. A concrete platform has been prepared to receive the boulder. From the depth of the clay pit in which it lay, and its great weight and irregular form, the lifting, carriage and setting up of the boulder is one of considerable difficulty. The boulder will be protected with wrought-iron railings, and no doubt will prove an object of abiding interest to the neighbourhood and to geologists generally.

News has been received from Sitten (Canton Valais, Switzerland) that, on Monday, Captain Spelterini attempted the passage over the Alps in his balloon the Vega. $\mathrm{He}$ was accompanied by Prof. Heim, of Zürich, Dr. Mauer, director of 